Artigos

Volume 8 - $2018 \mid$ n. 5

\title{
A Política de Valorização Profissional da SEMED de Unaí para os Professores: concepções de gestores em educação e sindicalistas
}

\author{
Eduardo Ferreira da Silva Caetano \\ Universidade de Brasília (UNB), Brasília/DF - Brasil \\ Érica Ferreira da Silva \\ Vilma Caetano de Jesus Ferreira
}

Associação Darwin de Educação e Pesquisa (ADEPE), Brasília/DF - Brasil

\section{Resumo}

O presente artigo busca evidenciar como gestores em educação e membros sindicais do município de Unaí avaliam a política de valorização, ou sua ausência, na realidade dos professores municipais do ensino fundamental do $1^{\circ}$ ao $5^{\circ}$ ano. Procura ainda revelar a visão desses gestores e sindicalistas sobre as contradições entre a determinação da Lei do Piso, Acórdão do STF e o seu não cumprimento por parte do governo local. Por fim, apresenta o posicionamento dos gestores em educação e sindicalistas sobre a carência de recursos financeiros para o financiamento da educação e sua materialização para a valorização dos professores municipais de Unaí.

Palavras-chave: Piso Salarial. Gestores em Educação. Sindicalistas. Valorização dos Professores.

\section{The professional appreciation policy of Unaí SEMED for teachers: conceptions of managers in education and trade unionists}

\section{Abstract}

This article aims to evidence how education managers and union members of the city of Unaí evaluate the appreciation policy or its lack in the reality of municipal elementary school teachers. It also seeks to uncover the perspective of these managers and trade unionists on the contradictions between what was established in the Starting Salary Law, the Supreme Court Judgment and its non-compliance by the local government. Lastly, it presents the position of education managers and trade unionists concerning the shortage of financial resources for the funding of education and its materialization for the appreciation of Unaí municipal teachers.

Keywords: Starting Salary. Managers in Education. Trade Unionists. Teacher Appreciation. 
A Política de Valorização Profissional da SEMED de Unaí para os Professores

\section{Percursos e Instrumentos Técnicos da Entrevista Semiestruturada}

O Município de Unaí, situado no noroeste de Minas Gerais, a $170 \mathrm{~km}$ de Brasília, faz parte da Região Integrada de Desenvolvimento do Distrito Federal e Entorno. Fundado em 1944 , apresenta uma população estimada de 82.887 habitantes. Tem como principal atividade econômica a agricultura e a pecuária. Sendo um dos maiores produtores de grãos do Brasil, tem destaque ora como maior produtor de feijão, ora como maior produtor de milho, além de soja, arroz, sorgo, trigo e outras culturas. É um município com grandes áreas destinadas à plantação de hortifrúti e conta também com inúmeras propriedades rurais que se dedicam à criação de gado.

A Rede Municipal de Ensino de Unaí atendeu, em 2015, aproximadamente oito mil alunos na educação infantil, na educação de jovens e adultos e no ensino fundamental. No ano de 2015, a Rede Pública Municipal de Unaí tinha 15 escolas municipais, 240 docentes, com salários de R\$ 980,60 para uma carga horária de 25 horas semanais, e teve 2.286 alunos matriculados no ensino fundamental do $1^{\circ}$ ao $5^{\circ}$ ano.

A Secretaria Municipal de Educação de Unaí conta com 34 unidades de ensino de educação básica, sendo 11 centros de educação infantil, 15 escolas municipais e oito privadas. Oferece níveis diversificados de ensino e atua em etapas e modalidades do ensino regular, com educação infantil, ensino fundamental do $1^{\circ}$ ao $9^{\circ}$ ano e educação de jovens e adultos. No ensino superior, possui três faculdades particulares e um polo da Universidade Estadual de Montes Claros. O Quadro 1 fornece uma visão da Secretaria Municipal de Educação de Unaí:

Quadro 1- Organograma da Secretaria Municipal de Educação de Unaí

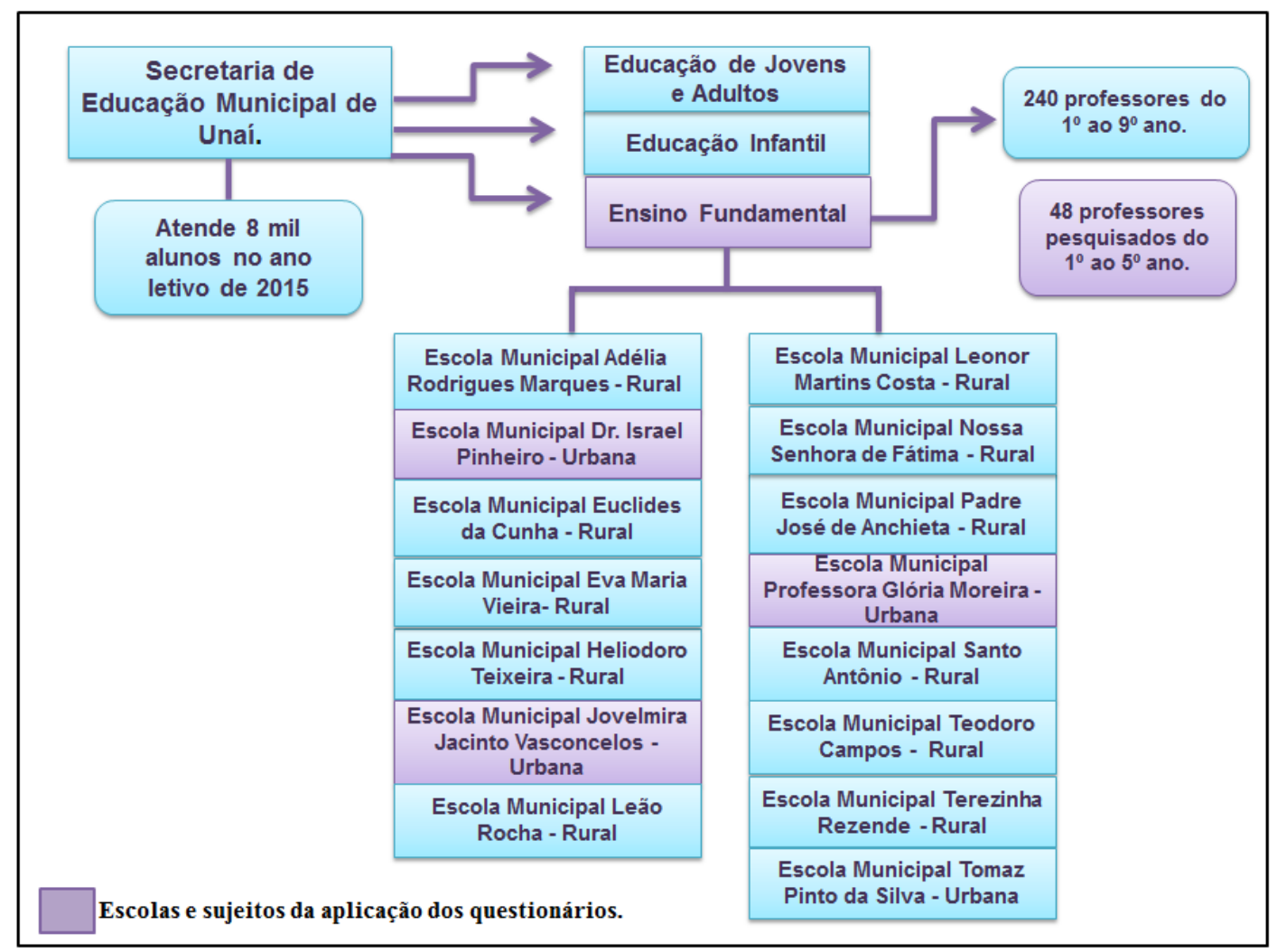

Fonte: Elaborado pelos autores, baseado em dados da SEMED e prefeitura de Unaí (2016). 
A Política de Valorização Profissional da SEMED de Unaí para os Professores

Optou-se pela aplicação de entrevistas semiestruturadas para 4 gestores: 2 gestores em educação e 2 membros sindicais. Selecionou-se um diretor da Rede de Ensino de Unaí, um dirigente sindical estadual do SIND/UTE-MG, um membro do sindicato municipal dos professores de Unaí e um ex-secretário da Rede Municipal de Unaí.

Os critérios para a escolha dos dois gestores educacionais (diretor e ex-secretário) da SEMED de Unaí foram: a) atuar no cargo de secretário de educação municipal, assessor ou diretor escolar; b) ter exercido o cargo no período entre 2008 e 2014; c) ser gestor que tivesse vínculo com a SEMED de Unaí; d) ser profissional de carreira que possui como fonte pagadora a Secretaria Municipal de Ensino de Unaí. Para a escolha dos dois membros sindicalistas, os critérios foram: a) ter atuação como dirigente sindical; b) ter atuado no cargo no período entre 2009 e 2014; c) ter atuado como professor entre 2008 e 2014.

As entrevistas foram realizadas em dias diferentes, nos meses de maio e junho de 2016 , conforme disponibilidades dos participantes, mediante Termo de Consentimento Livre e Esclarecido. Para resguardar os participantes, atribuiu-se a identificação: Dirigente Sindical Estadual III - para o representante do sindicato da SIND/UTE-MG; Dirigente Sindical Municipal IV - para representante do sindicato municipal dos professores de Unaí; Gestor II - para o diretor da Rede de Ensino de Unaí; e Gestor I - para o ex-gestor da Rede Municipal de Unaí, preservando-se, assim, a identidade dos entrevistados. Considerando os critérios de escolha e a transcrição integral da visão dos participantes das entrevistas, criou-se o Quadro 2 das entrevistas semiestruturadas, a seguir:

Quadro 2 - Sujeitos das Entrevistas Semiestruturadas

\begin{tabular}{|c|c|c|c|c|c|}
\hline Instituições & Cargo & Formação acadêmica & $\begin{array}{l}\text { Tempo na } \\
\text { profissão } \\
\text { professor }\end{array}$ & $\begin{array}{c}\text { Atuação nas } \\
\text { instituições }\end{array}$ & Anonimato \\
\hline $\begin{array}{c}\text { Secretaria } \\
\text { Municipal de } \\
\text { Educação de } \\
\text { Unaí }\end{array}$ & Ex-secretário & $\begin{array}{l}\text { Graduação em Letras, } \\
\text { pós-graduação em } \\
\text { Língua Portuguesa e } \\
\text { Literatura Brasileira e } \\
\text { mestrado profissional em } \\
\text { Administração }\end{array}$ & 17 anos & 2008 a 2012 & Gestor I \\
\hline $\begin{array}{c}\text { Escola } \\
\text { Municipal de } \\
\text { Unaí }\end{array}$ & $\begin{array}{c}\text { Diretor de } \\
\text { escola }\end{array}$ & $\begin{array}{l}\text { Graduação em Normal } \\
\text { Superior e pós- } \\
\text { graduação lato sensu }\end{array}$ & 25 anos & 2013 a 2015 & Gestor II \\
\hline $\begin{array}{l}\text { Sindicato Único } \\
\text { dos } \\
\text { Trabalhadores } \\
\text { em Educação }\end{array}$ & $\begin{array}{c}\text { Dirigente } \\
\text { Sindical } \\
\text { Estadual da } \\
\text { Regional da } \\
\text { Sind-UTE de } \\
\text { Unaí }\end{array}$ & $\begin{array}{l}\text { Graduado em Língua } \\
\text { Portuguesa e pós- } \\
\text { graduação lato sensu }\end{array}$ & 23 anos & 2011 a 2015 & $\begin{array}{l}\text { Dirigente } \\
\text { Sindical } \\
\text { Estadual III }\end{array}$ \\
\hline $\begin{array}{c}\text { Sindicato } \\
\text { Municipal dos } \\
\text { Professores } \\
\text { Municipal de } \\
\text { Unaí }\end{array}$ & $\begin{array}{l}\text { Membro } \\
\text { sindical }\end{array}$ & $\begin{array}{l}\text { Graduação em Normal } \\
\text { Superior e pós- } \\
\text { graduação lato sensu }\end{array}$ & 18 anos & 2009 a 2012 & $\begin{array}{l}\text { Membro } \\
\text { Sindical } \\
\text { Municipal } \\
\text { IV }\end{array}$ \\
\hline
\end{tabular}

Fonte: Quadro elaborado pelos autores - 2016 . 
A Política de Valorização Profissional da SEMED de Unaí para os Professores

Para analisar as respostas coletadas, selecionaram-se dados, informações, frases, sentenças, respostas singulares e vivências com maiores ocorrências, repetições e/ou similaridades nas falas dos quatro entrevistados. Optou-se por negritar trechos das respostas dos sujeitos com o objetivo de destacar e enfatizar as frases ou partes analisadas. As respostas dos gestores e sindicalistas foram sintetizadas conforme a seguir:

Quadro 3 - Categorias, Unidades Temáticas, Subunidades Temáticas e Frequências Resultantes da Pesquisa

\begin{tabular}{|c|c|c|c|}
\hline EIXOS DE ANÁLISE & $\begin{array}{l}\text { UNIDADES } \\
\text { TEMÁTICAS }\end{array}$ & $\begin{array}{l}\text { SUBUNIDADES TEMÁTICAS } \\
\text { (Respostas dos professores) }\end{array}$ & $\begin{array}{l}\text { FREQUÊNCIAS } \\
\text { (nº vezes que } \\
\text { repetiram) }\end{array}$ \\
\hline \multirow{8}{*}{$\begin{array}{c}\text { PISO COMO } \\
\text { VALORIZAÇÃO }\end{array}$} & Valoriza & Piso valoriza a categoria dos professores & 3 \\
\hline & \multirow{7}{*}{$\begin{array}{l}\text { Elementos que } \\
\text { valorizam }\end{array}$} & Aumento salarial & 4 \\
\hline & & Equipamentos eletrônicos (multimídia) & 2 \\
\hline & & Material didático & 2 \\
\hline & & Formação continuada & $\frac{2}{1}$ \\
\hline & & Número adequado de alunos por sala & 2 \\
\hline & & Plano de carreira & 2 \\
\hline & & Transporte seguro e confortável & 1 \\
\hline \multirow{4}{*}{ DESVALORIZAÇÃO } & \multirow{4}{*}{$\begin{array}{l}\text { Dificuldades } \\
\text { enfrentadas pelos } \\
\text { professores }\end{array}$} & Falta de apoio das famílias dos alunos & 3 \\
\hline & & Múltiplas funções dos professores & 1 \\
\hline & & Salas de aulas sem condições de trabalho & 2 \\
\hline & & Falta de material de multimídia & 2 \\
\hline \multirow{8}{*}{$\begin{array}{c}\text { DESCUMPRIMENTO DA } \\
\text { LEI } 11.738 / 2008\end{array}$} & \multirow{3}{*}{$\begin{array}{l}\text { Impede o } \\
\text { pagamento do } \\
\text { piso }\end{array}$} & Desinteresse dos gestores políticos & 3 \\
\hline & & Respeito a Lei de Responsabilidade Fiscal & 3 \\
\hline & & $\begin{array}{l}\text { Falta de complementação do Governo } \\
\text { Federal }\end{array}$ & 2 \\
\hline & \multirow{5}{*}{$\begin{array}{c}\text { O não } \\
\text { cumprimento do } \\
\text { piso afeta a } \\
\text { carreira do } \\
\text { professor }\end{array}$} & Estado de ansiedade na categoria & 1 \\
\hline & & Adoecimento e empobrecimento da classe & 1 \\
\hline & & Desgaste Emocional & 1 \\
\hline & & Desencantamento com a profissão & 1 \\
\hline & & Salário baixo & 1 \\
\hline \multirow{4}{*}{$\begin{array}{l}\text { VALORIZAÇÃO } \\
\text { PROFISSIONAL }\end{array}$} & \multirow{4}{*}{$\begin{array}{l}\text { Significado de } \\
\text { valorização e } \\
\text { remuneração }\end{array}$} & $\begin{array}{l}\text { A Lei Municipal } 56 / 2006 \text { de Unaí significou } \\
\text { avanços para a valorização dos professores } \\
\text { do município. }\end{array}$ & 1 \\
\hline & & $\begin{array}{l}\text { O cumprimento da promessa do governo } \\
\text { local de um salário base de } R \$ 2.500,00 \\
\text { para a categoria seria valorização e uma } \\
\text { remuneração melhor }\end{array}$ & 1 \\
\hline & & $\begin{array}{l}\text { Uma política que reconheça e valorize os } \\
\text { profissionais e não fique somente nas } \\
\text { palavras e de fato valorize todos os } \\
\text { profissionais da educação }\end{array}$ & 1 \\
\hline & & Valorizando o profissional da educação & 1 \\
\hline
\end{tabular}

Fonte: Elaborado pelos autores com base nos dados das entrevistas de 2016.

No Quadro 3, a primeira coluna apresenta os eixos de análise; a segunda, as unidades temáticas; a terceira, a subunidades temáticas (respostas dos gestores e dirigentes) e a quarta, as frequências das respostas.

Para problematização e análise da visão dos gestores e sindicalistas sobre a realidade concreta da política de valorização, empregada pelo governo municipal de Unaí, tomou-se a categoria contradição como meio facilitador para interpretação dos dados coletados (CURY, 2001, p. 30). 
A Política de Valorização Profissional da SEMED de Unaí para os Professores

\section{O Piso Salarial na Concepção de Gestores e Sindicalistas do Município de Unaí}

O piso salarial é componente indispensável para a valorização dos profissionais do magistério nacional. Tanto que no artigo 206, da Constituição Federal de 1988, como no inciso III do artigo 67, da LDB (Lei de Diretrizes e Bases da Educação Nacional), o piso salarial profissional nacional (PSPN) é apontado como um dos elementos base para fomentar a valorização dos profissionais do magistério público da educação (BRASIL, 1996).

O PNE (2014 -2024) apontou como estratégia a implementação do piso salarial nacional profissional como um fator das políticas de valorização para os profissionais do magistério Estratégia 17.4 (BRASIL, 2014). Nessa mesma linha de entendimento, para o estudioso Monlevade (2000), acredita-se que o pagamento do piso é um dos meios para a valorização do profissional da educação. Segundo suas palavras, "[...] o salário não é determinante para valorização do professor, mas simboliza um grau de valorização" (MONLEVADE, 2000, p. 269).

Perguntou-se aos participantes sobre o significado do piso como um elemento para a valorização dos professores. Responderam da seguinte maneira:

\footnotetext{
O piso como valorização é uma lei prometida desde 1950. É uma questão de valorizar os profissionais da educação oferecendo um salário que não pode ser menor do que o estabelecido pela lei. Os professores seriam remunerados por 25 horas em sala de aula e mais 15 horas de atividades extraclasse como o aperfeiçoamento profissional. $O$ cumprimento do piso faria com que os nossos professores não trabalhassem em 3 escolas para aumentar sua renda. Aqui é muito comum os profissionais trabalharem em três turnos (manhã, tarde e noite) sendo duas escolas, seja municipal ou estadual e outra estadual ou municipal ou mesmo duas escolas públicas e outra escola particular (DIRIGENTE SINDICAL ESTADUAL III).
}

Quando você tem uma remuneração melhor e você é bem remunerado isso reflete em todo o trabalho do profissional, se você está bem, a pessoa tem como ter uma melhor qualidade de vida, pois quando você tem um retorno melhor no seu trabalho, tem menos problema de saúde, é um profissional mais feliz, e dá o melhor de si. Vejo que o piso nacional pode ajudar muito o profissional em educação (MEMBRO SINDICAL MUNICIPAL IV).

Da mesma forma que os demais profissionais estudaram três, quatro ou cinco anos para terem formação, o professor também teve de estudar para ser professor. No entanto, outros profissionais que tem a mesma formação recebem salários melhores. Penso que a valorização em sentido profissional, para o profissional em educação, seria no sentido financeiro, ou seja, de melhores salários (GESTOR II).

No caso de Unaí, considerando o valor nacional 40 horas, o básico estava dentro do que se considera piso, porém havia uma perspectiva de melhorias levando-se em conta o valor do piso para 25 horas (GESTOR I).

A resposta concedida pelo Dirigente Sindical Estadual III corrobora com o sentido de piso estabelecido no $\S 1^{\circ}$ do artigo $2^{\circ}$, da Lei $11.738 / 2008$, que conceitua piso como "[...] o valor abaixo do qual não poderão fixar o vencimento inicial das carreiras do magistério público da educação básica, para a jornada de, no máximo, 40 horas semanais" (BRASIL, 2008). 
A Política de Valorização Profissional da SEMED de Unaí para os Professores

Segundo ainda $\S 3^{\circ}$ da Lei do Piso, os vencimentos iniciais referentes às demais jornadas de trabalho serão, no mínimo, proporcionais ao valor do vencimento para 40 horas. Sendo assim, caso a Administração Municipal de Unaí quisesse de fato pagar o valor do piso segundo a legislação, o valor do vencimento inicial proporcional para uma jornada de 25 horas seria de $R \$$ $1.334,77$ no ano de 2016 , ou $\mathrm{R} \$ 1.829,10$ em 2018 . Vale ressaltar que não se deve considerar benefícios trabalhistas obrigatórios para se alcançar o valor do piso.

O depoimento do Dirigente Sindical Estadual III mostra que o pagamento do piso pode significar diminuição na carga horária de trabalho dos profissionais de Unaí, pois é comum esses profissionais trabalharem em três turnos (manhã, tarde e noite) para obter uma renda suficiente para cobrir suas necessidades. Este fato corrobora com entendimento de Oliveira (2006), que a ausência do piso pode representar intensificação do trabalho docente e fazer com que os professores assumam mais que uma jornada de trabalho para obter maiores rendimentos. Também segundo as palavras de Pinto (2009, p. 56), os baixos salários oferecidos aos professores fazem com que estes procurem "[...] por mais aulas em outras redes de ensino".

Para Monlevade (2000, p. 279), a dobra da jornada de trabalho "desqualifica o ensino do professor" e cria "a multijornada e o multiemprego" para os professores devido ao descumprimento da legislação que institui o pagamento do piso aos docentes. O Dirigente Sindical Estadual III acredita no piso como direito, dívida e diminuição na carga horária de trabalho do professor.

Já no depoimento do Gestor II, a valorização por meio do piso deve ser no sentido financeiro, pois profissionais que têm a mesma formação que os professores "recebem salários melhores". Nesse entendimento, o Gestor II defende que, assim como outros profissionais, os professores deveriam receber salários equivalentes às demais profissões com requisitos semelhantes, pois o baixo salário de docente "não valoriza o professor" (MONLEVADE, 2000).

Essa valorização sugerida pelo Gestor II coincide com as palavras de Pinto (2009, p. 60), que acredita que a valorização salarial "[...] não é, necessariamente, um valor muito acima, mas simples e tão somente, o que já é pago por outras profissões". Percebe-se essa realidade concreta no Edital $n^{\circ} 1$, de 12 de dezembro de 2014, publicado pelo governo local do município de Unaí. O vencimento bruto ofertado foi de $R \$ 4.241,45$ para os cargos de psicólogo, nutricionista, assistente social e contador, em uma carga de 40 horas semanais, e teve como exigência curso superior, mesmo requisito requerido pela SEMED de Unaí no edital $n^{\circ} 30$, de 2015, para a contratação de professores municipais. No ano de 2015 , o vencimento básico bruto ofertado a essa categoria, ao contrário do oferecido às outras categorias, foi de $\mathrm{R} \$ 980,60$ para 25 horas, o que seria equivalente a $\mathrm{R} \$ 1.568,96$ para 40 horas. Nesse mesmo ano, sendo o valor do piso de $\mathrm{R} \$ 1.917,78$ para 40 horas, caso o pagamento fosse feito nos ditames do PSPN, o vencimento oferecido para 25 horas deveria ser equivalente a $R \$$ $1.198,61$, e não $\mathrm{R} \$ 980,60$.

Nesse sentido, o inciso IV, do artigo $4^{\circ}$, do Parecer CEB/CNE $n^{\circ} 2 / 2009$, que fixa as diretrizes nacionais para os planos de carreira e remuneração dos profissionais do magistério da educação pública, estabeleceu "[...] o reconhecimento da importância da carreira dos profissionais do magistério público e desenvolvimento de ações que visem à equiparação salarial com outras carreiras profissionais de formação semelhante" (BRASIL; MEC, 2009). 
A Política de Valorização Profissional da SEMED de Unaí para os Professores

Percebe-se, na fala do Gestor II, que a equiparação salarial não é uma realidade concreta para os professores municipais de Unaí, apesar de os mesmos possuírem formação semelhante a outras categorias.

O Membro Sindical Municipal IV destaca em seu depoimento que o piso pode significar "[...] uma melhor qualidade de vida, pois quando se tem uma remuneração melhor, isso reflete em todo o trabalho do profissional". Nesse sentido, o pesquisador Monlevade (2000, p. 279) pontua que "[...] os baixos salários levam o professor a aumentar a sua jornada de trabalho para compensá-los, roubando-lhe o tempo necessário para sua realimentação profissional".

Em movimento contrário ao pontuado pelos três participantes, o depoimento do Gestor I indaga que o vencimento básico do professor de Unaí em 2008, ano de sua gestão, "[...] estava dentro do que se considerava piso, tendo em vista que Unaí pagava o vencimento para 25 horas". Essa afirmação se revela uma contradição, pois piso é indivisível e irredutível. O piso é piso, independentemente de se trabalhar 25 ou 40 horas. Ademais, a Lei do Piso determina, em seu parágrafo $3^{\circ}$, o dever de fazer a proporcionalidade entre as horas, para efetivação do pagamento do piso aos professores.

Em suma, o piso valoriza porque, além de representar reconhecimento profissional, pode viabilizar a diminuição de carga horária, significar renda maior, possibilitar qualidade de vida e propiciar prestígio social à categoria. Para tanto, é essencial que os gestores educacionais compreendam o piso como um valor abaixo, no qual não poderá fixar o vencimento inicial à carreira do magistério para a carga no máximo de 40 horas (MONLEVADE, 2000; VIEIRA, 2012; CAETANO, 2017).

\section{O Significado de Valorização Profissional para Gestores e Sindicalistas do Município de Unaí}

A valorização profissional é uma maneira de reconhecer o trabalho e o desempenho de um trabalhador. No caso do professor, a valorização pode ser propiciada por cumprimento do pagamento do piso, formação continuada, condições adequadas de trabalho, plano de carreira e concurso público (BRASIL, 1996; CNTE, 2009; RONCA, 2010).

Para a Anfope (Associação Nacional pela Formação dos Profissionais da Educação), a valorização da carreira docente decorre de "[...] uma política global de formação dos profissionais da educação, contemplando a formação inicial, condições de trabalho, salário e carreira e formação continuada" (ANFOPE, 2001, p. 2). O documento final da Conae (2010) defende como elementos para efetiva valorização para os professores uma política articulada de forma orgânica de "[...] formação inicial e continuada, salários dignos, condições de trabalho, carreira de acesso via concurso público" (CONAE, 2010, p. 78).

A LDB elenca seis elementos que podem propiciar valorização aos professores. Para desvelar o entendimento dos gestores educacionais e sindicalistas do município de Unaí, perguntou-se que elementos expressam valorização para os professores. Fizeram os seguintes depoimentos:

Vejo a necessidade de reconhecer que todos os profissionais da sociedade passam pelas mãos dos professores. A questão de valorização não é só a coisa do salário. É preciso uma jornada de trabalho e progressão funcional para professores que buscam ter especialização, mestrado e doutorado (DIRIGENTE SINDICAL ESTADUAL III). 
A Política de Valorização Profissional da SEMED de Unaí para os Professores

É todo um conjunto, não dá para afirmar que esse ou aquele valoriza ou não, pois se minha sala de aula é estruturada com todos os equipamentos, automaticamente poderei ministrar uma aula melhor, terei condições adequadas para trabalhar. Se for bem remunerado, vou trabalhar mais feliz e terei uma vida melhor. É tudo interligado. Não dá para afirmar se esse ou aquele é fundamental, todos são importantíssimos (MEMBRO SINDICAL MUNICIPAL IV).

A denominação valorização do professor é ampla e discutível. Muitos consideram apenas a visão do salário. Sem dúvida é extremamente importante um bom salário para motivar o professor. Se tivéssemos um salário melhor, o professor poderia se dedicar a uma única escola e isso seria sem dúvida uma importante situação de valorização, mas a valorização passa por outras situações tais como: um plano de carreira bem estruturado, transporte seguro e confortável, material didático-pedagógico de apoio, equipamentos eletroeletrônicos, multimídias, formação tecnológica, possibilidade de curso de pós-graduação, mestrado, doutorado, prédios confortáveis e bem desenhados; laboratórios de química, física, biologia, entre outros. Tudo isso é parte do que se denomina valorização do professor (GESTOR I).

Seria a questão do aumento salarial, a reorganização do plano de carreira e fazer cumprir a quantidade de alunos em sala de aula. No que diz respeito à questão do número de alunos na sala de aula, a lei determina um tanto, mas na ação da nossa realidade somos obrigados a trabalhar com um número maior (GESTOR II).

A resposta do Dirigente Sindical Estadual III pontua que "[...] a questão da valorização não é só a coisa do salário. É preciso ter uma jornada de trabalho e ter uma promoção para os professores que busquem ter especialização, mestrado e doutorado". Segundo ADI 4.167, de 2011, do STF, não é possível "[...] falar em piso salarial sem falar de jornada de trabalho". Assim, a jornada pode ser considerada como uma vertente relevante para a valorização do professor, pois o inciso IV, do artigo 67, da Lei 9.394/96, fixa que os planos de carreira e a remuneração para os professores devem ser formulados com "[...] observância da jornada de trabalho dos docentes" (BRASIL, 1996).

Além disso, o depoimento do Dirigente Sindical Estadual III revela a necessidade de existência de definições claras de promoção funcional para os professores que "[...] busquem ter especialização, mestrado e doutorado". Segundo pesquisa de Gatti e Barreto (2009, p. 256), o pagamento de "[...] salários pouco atraentes e planos de carreira estruturados de modo a não oferecer horizontes claros, promissores e recompensadores no exercício da docência interferem na valorização social da profissão professor". Para o Dirigente Sindical Estadual III, há a necessidade de mecanismos recompensadores para os docentes que buscam a formação continuada.

O Membro Sindical Municipal IV enumera "[...] salas de aulas estruturadas com equipamentos, condição adequada de trabalho e uma boa remuneração para o professor" como elementos que, em sua opinião, expressam valorização. Esses fatores, além de valorizar a profissão do professor, são vertentes vitais para o desenvolvimento das atividades dos docentes (CNTE, 2009; OLIVEIRA, 2009).

O posicionamento do Membro Sindical Municipal IV assemelha-se às palavras do educador Freire (2006, p. 33), que tinha nas "[...] condições materiais condignas - salários decentes, escolas conservadas e reparadas em tempo como medidas burocráticas indispensáveis ao bom funcionamento das escolas". O Membro Sindical Municipal IV mostra 
A Política de Valorização Profissional da SEMED de Unaí para os Professores

que, para o professor ser valorizado, há necessidade de se oferecer condições de trabalho que possibilitem a realização e o desenvolvimento de suas atividades.

O Gestor I listou como fatores que expressam a valorização para os professores:

Salário maior, plano de carreira bem estruturado, transporte seguro e confortável, material didático-pedagógico de apoio, equipamentos eletroeletrônicos, multimídias, formação tecnológica; possibilidade de curso de pós-graduação, mestrado, doutorado; prédios confortáveis e bem desenhados; laboratórios de química, física, biologia, entre outros, tudo isso é parte do que se denomina valorização do professor (GESTOR I).

Essas vertentes coincidem com o entendimento de Brzezinski (2008, p. 243), que sugere o "[...] aperfeiçoamento profissional continuado, piso salarial profissional, progressão funcional baseada na titulação ou habilitação e condições adequadas", como elementos vitais para a valorização do professor. O Gestor I pontou fatores como equipamentos de multimídias e formação tecnológica como eixos que podem expressar a valorização ao professor.

Segundo as palavras de Santos (2002, p. 49), "[...] o uso de novos equipamentos e tecnologias estabelece aos professores novos valores de acordo com as exigências de uma época universalizada e sujeita a alterações". O Gestor I elencou também a necessidade de prédios confortáveis e bem desenhados. Este corrobora com o entendimento de Paro (2012, p. 606), que defende que os professores carecem de ter "[...] edifício escolar organizado de forma a atender, confortavelmente, vários grupos pequenos de estudantes que participam das atividades educativas de maneira mais livre e espontânea".

Já a entrevista do Gestor II relacionou "[...] fazer cumprir a quantidade de alunos em sala de aula". O cumprimento desse fator é fundamental para a valorização da categoria. A pesquisa de Oliveira e Feldfeber (2006) aponta salas de aulas superlotadas como um dentre vários problemas e desafios enfrentados diariamente pela maioria da classe dos professores públicos.

O número determinado de alunos, citado pelo Gestor II, é defendido pela Conae desde 2010, como outra forma de valorizar os profissionais da educação, por isso fixou "[...] um número máximo de 20 alunos por turma para o ensino fundamental" (CONAE 2010, p. 78-79).

A situação vivenciada pelos professores do município de Unaí mostra-se contrária a essa determinação. A contradição entre a legislação e a realidade dos professores da SEMED de Unaí aparece na fala do Gestor II que argumenta que:

No que diz respeito à questão do número de alunos na sala de aula a lei determina um tanto, mas na ação da nossa realidade somos obrigados a trabalhar com um número maior. Infelizmente, a gente não sabe se segue a normativa da lei ou se segue as nossas normativas de nossa realidade (GESTOR II).

Além de os professores terem um número de 20 alunos por turma, conforme defendido pelo Gestor II, os sindicalistas e os gestores apontam ainda jornada de trabalho, condições adequadas, boa remuneração, salas de aulas bem equipadas, plano de carreira, equipamentos de multimídia, transporte seguro e confortável, material didático-pedagógico e formação continuada como elementos que expressam valorização (VIEIRA, 2012).

Para ampliar a análise perguntou-se sobre valorização e remuneração para os professores de Unaí. Obtiveram-se os seguintes depoimentos: 
A Política de Valorização Profissional da SEMED de Unaí para os Professores

Aqui na SEMED-Unaí há uma promessa para o pagamento do piso nacional, no novo plano de carreira a ser aprovado. Estamos marcando uma greve geral para todo o Estado de Minas Gerais para exigir o cumprimento da promessa do governo atual, que, quando era candidato, disse que pagaria o piso para a categoria. Precisamos de uma política que reconheça e valorize os profissionais e não fique somente nas palavras e de fato valorize todos os profissionais em educação. Isso é fundamental, sabemos que a educação não transforma a sociedade, transforma o ser humano, e o ser humano é que transforma a sociedade. Só seremos cidadãos se soubermos quais os nossos direitos e deveres como cidadãos. A escola tem o papel de fazer essa contribuição para a sociedade (DIRIGENTE SINDICAL ESTADUAL III).

Valorizando o profissional da educação, ele vai trabalhar melhor, vai ter um rendimento melhor, vai ter saúde e o emocional será melhor, pois, se o profissional está bem emocionalmente, seu aproveitamento também será melhor no trabalho. A remuneração é um reflexo disso aí, pois se somos bem remunerados, vamos ter uma melhor qualidade de vida em todos os aspectos. Em todos os sentidos, o retorno será muito melhor para o profissional, para o município e para a comunidade no geral (MEMBRO SINDICAL MUNICIPAL IV).

A reorganização do novo plano de carreira tem a promessa de que o professor terá um salário de $R \$ 2.500,00$ para 25 horas semanais. É uma promessa ou sonho. Caso realmente este plano seja aprovado, a maioria dos profissionais afirma que trabalharia apenas em um turno. Com isso, teremos qualidade de vida para nós e para doarmos aos alunos. Muitos aqui trabalham três turnos, manhã, tarde e noite, para suprir as necessidades de suas famílias (GESTOR II).

A partir de 2005, foram feitas grandes e significativas mudanças para valorizar o profissional docente. A Lei $n^{\circ}$ 56/2006 que instituiu o Estatuto e o Plano de Carreira do Magistério estabeleceu regras claras sobre muitos aspectos tais como concurso público, exigência de curso superior, promoções e progressões, o sistema de lotação dos servidores, transporte para professores, construção, ampliação e reformas de escolas e creches. Porém, muito ainda precisa ser feito, por exemplo, oferta de vagas em creches e pré-escolas, possibilidade de o docente ter carga-horária reduzida para mestrado e doutorado, sistema de promoção por mérito, melhorar as estruturas físicas, tecnológicas, entre outras (GESTOR III).

A resposta do Dirigente Sindical Estadual III relaciona a valorização profissional à necessidade de um efetivo plano de carreira que considere e recompense os anos de experiências e a formação continuada do professor. Esse sentido de política de valorização é defendido pelo sindicalista quando diz:

Sou responsável aqui pela unidade de Unaí do SIND/UTE-MG, mas, como professora, tenho pós-graduação lato sensu e mais de 20 anos na carreira, tenho salário de $\mathrm{R} \$$ $2.000,00$. Não há valorização se você comparar um professor que tem 23 anos na carreira e um que está começando, o professor experiente receber $R \$ 600,00$ ou $R \$$ 800,00 a mais. Precisamos de uma política que reconheça e valorize os profissionais e não fique somente nas palavras, mas de fato valorize todos os profissionais em educação (DIRIGENTE SINDICAL ESTADUAL III).

Essa argumentação encontra-se determinada no inciso VI, do artigo 67 da LDB, que aponta os estatutos e planos de carreira do magistério, dos sistemas estaduais e municipais de educação como valorização para os profissionais da educação (BRASIL, 1996). Para isso se concretizar é necessário que o plano de carreira da categoria ofereça rendimento que seja 
A Política de Valorização Profissional da SEMED de Unaí para os Professores

equivalente à progressão funcional e à formação adquirida pelo docente no transcorrer de sua vida profissional.

Conforme exemplificado pelo Dirigente Sindical Estadual III, "[...] não há valorização se você comparar um professor que tem 23 anos na carreira e um que está começando, o professor experiente receber $\mathrm{R} \$ 600,00$ ou $\mathrm{R} \$ 800,00$ a mais que o iniciante na carreira". A Lei Complementar $n^{\circ}$ 56, de 30 de outubro de 2006, que instituiu o Estatuto e o Plano de Cargos, Carreira e Remuneração do Magistério Público de Unaí não tem consistido em um conjunto de normas estabelecidas com o objetivo de valorizar as condições e o processo de movimentação na carreira, estabelecendo a progressão funcional, os adicionais, os incentivos e as gratificações devidas, assim como os correspondentes critérios e escalas de evolução da remuneração (UNAÍ, 2006).

Para o Membro Sindical Municipal IV, significa valorização profissional a melhoria na qualidade de vida do professor com a valorização docente por meio de uma melhor remuneração para a categoria (BRASIL, 1996). Entretanto, a realidade concreta dos professores no município de Unaí não é a de serem bem remunerados. Conforme exposto na fala do Dirigente Sindical Estadual III, um professor com 23 anos de trabalho e pós-graduação lato sensu recebe $\mathrm{R} \$ 2.000,00$. Este fato confirma o estudo de Nascimento e Silva (2014, p. 46), que revela que "[...] os ocupantes de postos de trabalho típicos de atividades pedagógicas recebem remuneração média $20 \%$ inferior aos de postos ocupados por profissionais de outras carreiras típicas de nível superior".

Para a remuneração possibilitar valorização, esta pode ser significada como "[...] dinheiro recebido pelo trabalhador em razão da prestação de serviços, proveniente dos empregadores ou de terceiros" (MARQUES; ABUD, 2008, p. 51). Isso porque o valor da remuneração revela o nível de reconhecimento do serviço prestado, e, para valorizar o professor, requer-se "[...] não um valor muito acima, mas simples e tão somente, o que já é pago para outras profissões" (PINTO, 2009, p. 60). Na entrevista do Gestor II, nota-se que a valorização no seu entendimento se dará quando:

\begin{abstract}
A reorganização do novo plano de carreira tem a promessa de que o professor terá um salário de $R \$ 2.500,00$ para 25 horas semanais. É uma promessa ou sonho. Caso realmente este plano seja aprovado, a maioria dos profissionais afirma que trabalhariam apenas em um turno. Com isso, teremos qualidade de vida. Pois muitos aqui trabalham três turnos, manhã, tarde e noite, para poder suprir as necessidades de suas famílias (GESTOR II).
\end{abstract}

O Gestor II aponta para a promessa do governo local de propiciar salário de $\mathrm{R} \$ 2.500,00$ como significado de valorização profissional e qualidade de vida para a categoria. Segundo ele, se a valorização profissional ocorre pelo aumento da remuneração, "[...] a maioria dos professores municipais trabalhariam apenas em um turno, pois muitos aqui trabalham três turnos, de manhã, tarde e noite, para poder suprir as necessidades de suas famílias" (Gestor II). Esses estudos mostram que os professores assumem aulas em mais de um período, o que acarreta maior desgaste e algumas consequências negativas para o seu trabalho (OLIVEIRA, 2006; ASSUNÇÃO; OLIVEIRA, 2009; CAETANO, 2017).

A resposta do Gestor I foi:

A partir de 2005, foram feitas grandes e significativas mudanças para valorizar o profissional docente. A Lei 56/2006, Plano de Carreiras do Magistério, estabeleceu regras claras sobre muitos aspectos tais como concurso público, exigência de curso superior, 
A Política de Valorização Profissional da SEMED de Unaí para os Professores

promoções e progressões, o sistema de lotação dos servidores, transporte para professores, construção, ampliação e reformas de escolas e creches (GESTOR I).

Esse depoimento relaciona a valorização profissional para os professores municipais e a Lei $n^{0} 56 / 2006$, como oposto à resposta do Gestor II, que acredita justamente que a valorização para a categoria só ocorrerá com a reorganização dessa mesma lei. Nas palavras do Gestor I, essa lei que vigora desde 2006 tem feito com que os professores trabalhem "[...] três turnos, manhã, tarde e noite, para poder suprir as necessidades de suas famílias". Esta legislação deveria propiciar valorização, mas não tem cumprido sua finalidade.

No campo das políticas educacionais, não têm sido oferecidas condições favoráveis ao trabalho docente, tais como infraestrutura adequada, material escolar, plano de carreira, salários dignos e formação continuada. A Lei Municipal $n^{\circ} 56$, de 2006 , até determina os meios para a concretização de valorização profissional para o professor, no entanto, não está em sua totalidade materializada na vida profissional dos professores do município de Unaí.

O Dirigente Sindical Estadual III atribui o não pagamento do piso para os professores municipais por:

Falta de interesse dos gestores políticos [...]. Percebo que falta empenho dos gestores municipais, porque se o município de Unaí não tem condições para pagar o piso aos professores que façam o pedido para a União complementar. Falta mesmo é comprometimento e interesse dos gestores políticos (DIRIGENTE SINDICAL ESTADUAL III).

Nesse depoimento, enumera-se como causas para o não cumprimento do piso, para os professores municipais, "[...] falta de interesse e comprometimento dos gestores políticos". Isso vai ao encontro das palavras de Nascimento (2011, p. 107), que afirma que "[...] a ampliação da valorização do magistério ficou prejudicada devido à fragilidade dos instrumentos de controle e o descompromisso dos gestores públicos com a valorização do magistério".

Para a concretização do cumprimento do pagamento do piso, o reconhecimento e a valorização da profissão do professor, são imprescindíveis o interesse e o empenho político dos governos subnacionais. Assemelha-se ao que defende Campos e Cruz (2009), que afirma que a disponibilidade de recursos "[...] é condição necessária, porém não suficiente, para se consolidar uma educação pública de qualidade. Bom senso, vontade política e discernimento por parte dos governantes também são metas desejáveis e essenciais" (CAMPOS; CRUZ, 2009, p. 392).

A fala do Gestor I diz que "[...] os prefeitos esbarram na Lei Responsabilidade Fiscal, e a maioria das prefeituras está no limite máximo e, mesmo tendo os recursos, os prefeitos não podem extrapolar para não serem multados ou penalizados". O Membro Sindical Municipal IV acredita que "[...] a folha de pagamento está ultrapassada pelo limite da Lei de Responsabilidade Fiscal". Por fim, o Gestor II justifica como desculpa "[...] não ter recursos e necessidade de respeito da LRF que não pode ultrapassar".

Todos esses apontamentos elencados como obstáculos econômicos para o impedimento do pagamento do piso não são suficientes, em sua totalidade, para explicar ou justificar o não cumprimento de determinação de uma lei federal e ordem judicial. Essa situação concreta apresenta contradição, pois os governos subnacionais têm norma legal que os obriga a cumpri-la, mas não a cumprem (SAVIANI, 2009, p. 16). Os governos necessitam 
A Política de Valorização Profissional da SEMED de Unaí para os Professores

"[...] estar atentos e planejar devidamente os gastos com os profissionais do magistério, especialmente para a necessidade de se ter um plano de carreira atualizado, instituído por meio de lei específica" (BRASIL, 2010, p. 30). Para desvelar as consequências do não cumprimento do piso na vida profissional e pessoal dos professores municipais, perguntou-se aos gestores e aos membros sindicais como o descumprimento da lei afeta a carreira dos professores.

Os entrevistados apresentaram as seguintes falas:

O descumprimento da lei gera um estado de ansiedade muito grande no profissional. Quando o presidente sancionou a Lei do Piso, ele queria que os professores fossem valorizados. A lei foi feita e sancionada, mas ela não é cumprida. Isso adoece a categoria por esperar algo que deve ser cumprido, afinal é uma Lei Federal, provoca desgaste profissional, adoecimento da categoria, empobrecimento, porque quem começa a trabalhar na SEMED-Unaí hoje recebe $\mathrm{R} \$ 1.000,00$, um profissional que tem curso superior. O professor hoje é proletariado e assim ele tem que ter várias jornadas para poder sobreviver. Ele não vive, ele sobrevive (DIRIGENTE SINDICAL ESTADUAL III).

Já mencionei anteriormente que há certo desencanto dos profissionais docentes com os rumos da educação no país. Parece-me que as metodologias estão ultrapassadas, professores estão sem estímulos, sem encantamentos com a profissão. Falta muito em termos de estrutura física, mas falta também ideologia educadora e responsabilidade social. Parece ser uma perda de orientação (GESTOR I).

A Lei do Piso está afetando muito os professores em fim de carreira, porque eles têm dificuldades e estão esperando o cumprimento do pagamento do piso e do plano de carreira para terem uma condição melhor. Isto está impedindo que eles tenham o merecido descanso. Os professores ativos têm sofrido com a questão emocional de ficar na expectativa, de ficar esperando e não acontecer (MEMBRO SINDICAL MUNICIPAL IV).

Carreira em si não afeta. Porque você vai seguir sua carreira, mas descumpre a questão salarial, pois o salário continua abaixo do piso. Com isso, você não sabe se o Governo Federal ou Poder Local que está mentindo (GESTOR II).

As consequências apresentadas pelo Dirigente Sindical Estadual III foram "[...] desgaste profissional, adoecimento da categoria, empobrecimento, professor proletariado e, assim, ter várias jornadas de trabalho para poder sobreviver". Os fatores listados nessa fala ocorrem devido aos baixos salários, acumulo de jornada de trabalho e a necessidade de aumento da renda. Nessa mesma linha, Gouveia et al. (2006) que afirmam que:

A necessidade de manter vários empregos ou atividades para a geração de recursos complementares, devido aos baixos salários, também foi indicada como fator de desmotivação, pois sequer podem os professores se atualizar para oferecer melhores níveis de qualidade (GOUVEIA et al., 2006, p. 267).

Essa situação de descaso é a realidade dos professores de Unaí em virtude de as redes de ensino permitirem o aumento de carga horária e de estabelecerem jornadas que possibilitam aos docentes possuir duas ou três cargas horárias em redes diferentes (PINTO, 2009). O Dirigente Sindical Estadual III listou também o adoecimento da categoria provocado pelos salários baixos e discrepantes frente ao grau de responsabilidade da atividade exercida pelo professor municipal de Unaí (ASSUNÇÃO; OLIVEIRA, 2009).

Por fim, o Gestor I apontou desencanto, o Gestor II, salário continua baixo, e o Membro Sindical Municipal IV desgaste emocional em esperar e não acontecer. Esses fatores 
A Política de Valorização Profissional da SEMED de Unaí para os Professores

coincidem com o pensamento de Gouveia et al. (2006), que acredita que os baixos salários e a falta de plano de carreira adequado propiciam desencanto com a profissão professor. Esse desencanto provoca a naturalização da ausência de valorização profissional.

\section{Considerações Finais}

Desde o Império, o descaso com a oferta de ensino para a maioria da população trabalhadora e a ausência de políticas de valorização para o magistério foram justificadas pela insuficiência de recursos financeiros. Essa carência de recursos financeiros, a negligência com o financiamento da educação e a desorganização da educação contribuíram para a materialização da baixa remuneração, para a escassez de material didático, a precariedade das instalações escolares, a desmotivação e o descontentamento na realidade cotidiana dos professores.

Independente do contexto histórico, a desculpa do governo central e dos governantes mineiros para inviabilização do pagamento de bons ordenados, condições adequadas de trabalho e oferecimento de melhores incentivos de progressão funcional para a carreira dos professores foi a falta de recursos orçamentários e financeiros para financiar a educação (FARIA FILHO, 1998).

O piso é fruto, considerando as palavras de Marx (1983, p. 22), de "[...] uma história de luta de classe", pois ocorreram diversas mobilizações em nível nacional, paralisações, passeatas e congressos da categoria para que se chegasse à criação e a promulgação da Lei Federal 11.738/2008, a chamada Lei do Piso. Conforme defendido pela Anfope (2001, p. 9), essa lei, além de propiciar valorização profissional e social, é um "[...] instrumento de luta e resistência contra a degradação da profissão de professor do magistério público".

Os participantes dessa investigação conceituaram o piso como fator fundamental para a valorização, pois pode representar a diminuição na carga horária de trabalho no sentido de receber o mesmo que outras categorias ou ter uma melhor qualidade de vida (MONLEVADE, 2000; VIEIRA, 2012).

Os gestores e sindicalistas citaram como condições de trabalho presentes no dia a dia dos professores municipais, salas superlotadas, falta de material didático, material inadequado à realidade dos alunos e escassez de carteiras nas salas de aula. Para eles, essas péssimas condições de trabalho propiciam diminuição do reconhecimento social, desvalorização e desinteresse com a profissão (OLIVEIRA, 2004; LIBÂNEO, 2002; CAETANO, 2017).

$\mathrm{Na}$ análise dos sindicalistas e gestores, os elementos que expressam valorização para os professores são jornada de trabalho adequada, promoção salarial equivalente ao esforço do docente, salas bem equipadas, boa remuneração, plano de carreira estruturado e fazer cumprir o número máximo de aluno por turma. Talvez não se deva buscar no Estado capitalista a valorização profissional, e sim construir nos movimentos sociais, sindicais e entidades acadêmicas a valorização que se precisa e exigir que o governo a cumpra.

Percebe-se nas falas dos sindicalistas e gestores em educação, participantes desse estudo, mesmo com visões diferentes, que o cumprimento do piso, as condições adequadas de trabalho e a boa recompensa pela formação continuada podem melhorar 
A Política de Valorização Profissional da SEMED de Unaí para os Professores

consideravelmente a realização do trabalho do professor como também pode possibilitar a valorização profissional e social da profissão.

\section{Referências}

ANFOPE. Documento Final do x Encontro Nacional. Belo Horizonte, 2001. Disponível em <www.lite.fae.unicampi.br/anfope> Acesso em: 10 out. 2014.

ASSUNÇÃO, Ada Ávila; OLIVEIRA, Dalila Andrade. Intensificação do Trabalho e Saúde os Professores. Educação \& Sociedade, Campinas, v. 30, n. 107, 2009.

BRASIL. Lei no 9.394 de 20 de dezembro de 1996. Estabelece as Diretrizes e Bases da Educação Nacional. Diário Oficial da União, Brasília, 1996. Disponível em: <http://www.planalto.gov.br/ccivil_03/leis/L9394.htm>. Acesso em: 20 nov. 2017.

BRASIL. Lei $n^{\circ} 11.738$, de 16 de julho de 2008. Regulamenta a Alínea "e" do Inciso III do Caput do art. 60 do Ato das Disposições Constitucionais Transitórias, para Instituir o Piso Salarial Profissional Nacional para os Profissionais do Magistério Público da Educação Básica. Diário Oficial da União, Brasília, 2008.

BRASIL. Ministério de Educação. Parecer n²/2009. Diário Oficial da União, Brasília, 2009. BRASIL. Supremo Tribunal Federal. Ação Direta de Inconstitucionalidade $\mathbf{n}^{0}$ 4.167. Brasília: STF, 2011.

BRASIL. Plano Nacional de Educação. Lei n ${ }^{0}$ 13.005, de 25 de junho de 2014. Aprova o Plano Nacional de Educação para o decênio 2014-2024 e dá outras providências. Diário Oficial da União, Brasília, 2014. Disponível em: <http://www2.camara.leg.br/legin/fed/lei/2014/lei13005-25-junho-2014-778970>. Acesso em: 13 ago. 2014.

BRZEZINSKI, Iria. LDB - Dez Anos Depois: reinterpretação sob diversos olhares. São Paulo: Editora Cortez, 2008.

CAETANO, Eduardo Ferreira da Silva. Os Ordenados e a Baixa Remuneração dos Professores das Primeiras Letras em Minas Gerais. Revista Fineduca, Porto Alegre; São Paulo, v. 7, n. 10, 2017.

CAMPOS, Bruno César Campos; CRUZ, Breno de Paula Andrade. Impactos do FUNDEB sobre a Qualidade do Ensino Básico Público: uma análise para os Municípios do Estado do Rio de Janeiro. Revista de Administração Pública, Rio de Janeiro, v. 43, n. 2, p. 371-93, 2009.

CONAE. Conferência Nacional de Educação. Construindo o Sistema Nacional Articulado de Educação: o Plano Nacional de Educação, diretrizes e estratégias; Documento-Base. Brasília: MEC, 2010.

CNTE. Confederação Nacional dos Trabalhadores em Educação. Diretrizes para a Carreira e Remuneração. Cadernos de Educação, Brasília, v. 14, n. 21, 2009.

CURY, Carlos Roberto Jamil. A Educação como Desafio na Ordem Jurídica. Belo Horizonte: Autêntica, 2001.

FARIA FILHO, Luciano Mendes. Culturas e Práticas Escolares: escrita, aluno e corporeidade. Cadernos de Pesquisa, São Paulo, n. 103, 1998. 
A Política de Valorização Profissional da SEMED de Unaí para os Professores

FREIRE, Paulo. Pedagogia do Oprimido. Rio de Janeiro: Paz e Terra, 2006.

GOUVEIA, Andréa Barbosa et al. Condições de Trabalho Docente, Ensino de Qualidade e Custo-Aluno-Ano. Revista Brasileira de Política e Administração da Educação, Brasília, v. 22, n. 2, p. 253-276, 2006.

LIBÂNEO, José Carlos. O Professor e a Construção da sua Identidade Profissional. Goiânia: Alternativa, 2002.

MARX, Karl; ENGELS, Friedrich. O Capital. Rio de Janeiro: Graal, 1983.

MARQUES, Fabíola; ABUD, Cláudia José. Direito do Trabalho. São Paulo: Atlas, 2008.

MONLEVADE, João Antônio Cabral. Valorização Salarial dos Professores: o papel do piso salarial profissional nacional como instrumento de valorização dos professores de educação básica pública. 2000. Tese (Doutorado em Educação) - Universidade Estadual de Campinas, Campinas, 2000.

NASCIMENTO, João Batista. O Financiamento da Educação Básica e a Política de Fundos em Goiás (1998 a 2011): municipalização, redistribuição dos recursos e (des)valorização do magistério. 2011. Dissertação (Mestrado em Educação) - Universidade Federal de Goiás, Goiânia, 2011.

NASCIMENTO, Paulo Meyer; SILVA, Carolina Andrade; SILVA, Paulo Henrique Dourado. Subsídios e Proposições Preliminares para um Debate sobre o Magistério da Educação Básica no Brasil. RADAR - tecnologia, produção e comércio exterior, IPEA, on-line, n. 32, $2014 . \quad$ Disponível em: <http://www.ipea.gov.br/agencia/images/stories/PDFs/radar/140508_radar32_cap3>. Acesso em: 10 out. 2017.

OLIVEIRA, Dalila Andrade. A Reestruturação do Trabalho Docente: precarização e flexibilização. Educação \& Sociedade, Campinas, v. 25, n. 89, p. 1127-1144, 2004.

OLIVEIRA, Dalila Andrade. Regulação Educativa na América Latina: repercussões sobre a identidade dos trabalhadores docentes. Educação em Revista, Belo Horizonte, n. 44, p. 209227, 2006.

OLIVEIRA, Dalila Andrade; FELDFEBER, Myriam. Políticas Educativas y Trabajo Docente. Buenos Aires: Centro de Publicaciones Educativas y Material Didático, 2006.

OLIVEIRA, Ricardo Costa de. O Silêncio dos Vencedores: genealogia, classe dominante e estado do Paraná. Curitiba: Moinho do Verbo, 2009.

PARO, Vitor Henrique. Administração Escolar: introdução crítica. São Paulo: Cortez Editora, 2012.

PINTO, José Marcelino Rezende. Remuneração adequada do professor: desafio à educação brasileira. Revista Retratos da escola, Brasília, v. 3, n. 4, 2009.

RONCA, Antonio Carlos Caruso. Formação Inicial e Continuada de Professores: Políticas e Desafios. Brasília: Mais Gráfica Editora, 2010.

SANTOS, Selma Ferro. Processos de Desenvolvimento de "Novas Práticas": apropriação e uso de novas tecnologias. Rio de Janeiro: DP\&A, 2002. 
A Política de Valorização Profissional da SEMED de Unaí para os Professores

SAVIANI, Dermeval. Formação de Professores: aspectos históricos e teóricos do problema no contexto brasileiro. Revista Brasileira de Educação, Rio de Janeiro, v. 14, n. 40, p. 143155, 2009.

UNAÍ. Lei Complementar $n^{\circ} 56$, de 30 de outubro de 2006. Dispõe sobre o Estatuto e o Plano de Cargos, Carreiras e Remuneração do Magistério Público do Município de Unaí e dá outras providências. Prefeitura Municipal, Unaí, $2006 . \quad$ Disponível: <www.prefeituraunai.mg.gov.br/pmu>. Acesso em: 10 abril 2014.

VIEIRA, Juçara Dutra. Piso Salarial para os Educadores Brasileiros: quem toma partido? Campinas: Autores Associados, 2012.

Eduardo Ferreira da Silva Caetano é mestre em Educação pela Universidade de Brasília (UNB), MBA em Administração Pública pela Escola de Administração e Negócios, graduado em Direito pelo Instituto Processus de Brasília, graduado em Pedagogia pela Universidade de Brasília. Atua na Subsecretária de Planejamento e Orçamento do Ministério da Educação desenvolvendo estudos e acompanhamentos orçamentários e jurídicos das Universidades e Institutos Federais. É servidor do Instituto Federal de Brasília cedido ao Ministério da Educação.

E-mail: eduardofscaetano@gmail.com

Érica Ferreira Silva é graduada em Pedagogia pela Universidade de Brasília e pós-graduada em Educação pela Associação Darwin de Educação e Pesquisa. Atua como professora da Secretaria de Educação do Distrito Federal.

E-mail: ericaferreira.silva@yahoo.com.br

Vilma Caetano de Jesus Ferreira possui pós-graduação em Educação pela Associação Darwin de Educação e Pesquisa, graduação em Letras Português pela Faculdade Jesus Maria José e graduação em Pedagogia pela Faculdade de Administração e Ciências, Educação e Letras. Atua como professora da Secretaria de Educação do Distrito Federal. E-mail: vilmacjferreira@gmail.com 


\title{
Editores do volume 8
}

José Marcelino de Rezende Pinto - Universidade de São Paulo, São Paulo/SP, Brasil

Nalú Farenzena - Universidade Federal do Rio Grande do Sul, Porto Alegre/RS, Brasil

\section{Comitê Editorial}

José Marcelino de Rezende Pinto - Universidade de São Paulo, Brasil

Juca Gil - Universidade Federal do Rio Grande do Sul, Brasil

Theresa Adrião - Universidade Estadual de Campinas, Brasil Ângelo

Ricardo de Souza - Universidade Federal do Paraná, Brasil

Márcia Aparecida Jacomini - Universidade Federal de São Paulo, Brasil

\section{Conselho Editorial}

\section{Alejandro Morduchowicz}

Universidad Pedagógica, Provincia de Buenos Aires, Argentina

Fernanda Saforcada

Universidade de Buenos Aires, Argentina

Jacques Velloso

Universidade de Brasília, Brasil

João Monlevade

Senado Federal, Brasil

Jorge Abrahão de Castro

Instituto de Pesquisa Econômica Aplicada / IPEA, Brasil

Juca Gil

Universidade Federal do Rio Grande do Sul, Brasil

Lisete Regina Gomes Arelaro

Universidade de São Paulo, Brasil

Luis Carlos Sales

Universidade Federal do Piauí, Brasil

Luiz de Sousa Junior

Universidade Federal da Paraíba, Brasil

Luiz Fernandes Dourado

Universidade Federal de Goiás, Brasil

Magna França

Universidade Federal do Rio Grande do Norte, Brasil

\section{Maria Beatriz Luce}

Universidade Federal do Pampa, Brasil

Universidade Federal do Rio Grande do Sul, Brasil

Marcos Edgar Bassi

Universidade Federal do Paraná, Brasil

\author{
Maria Dilnéia Espíndola Fernandes \\ Universidade Federal de Mato Grosso do Sul, Brasil \\ Nalú Farenzena \\ Universidade Federal do Rio Grande do Sul, Brasil \\ Nelson Cardoso do Amaral \\ Universidade Federal de Goiás, Brasil \\ Nicholas Davies \\ Universidade Federal Fluminense, Brasil \\ Rosana Evangelista Cruz \\ Universidade Federal do Piauí, Brasil \\ Rosana Gemaque \\ Universidade Federal do Pará, Brasil \\ Robert E. Verhine \\ Universidade Federal da Bahia, Brasil \\ Romualdo Portela de Oliveira \\ Universidade de São Paulo, Brasil \\ Theresa Adrião \\ Universidade Estadual de Campinas, Brasil \\ Tristan McCowan \\ University of London, Reino Unido \\ Vera Jacob \\ Universidade Federal do Pará, Brasil \\ Vera Peroni \\ Universidade Federal do Rio Grande do Sul, Brasil \\ Vitor Henrique Paro \\ Universidade de São Paulo, Brasil
}

\section{Equipe editorial}

Apoio ao Comitê Editorial: Patrícia Balthazar Garcia

Diagramação, Revisão de português e normalização: Edson Leonel de Oliveira

Revisão de inglês: Ananyr Porto Fajardo 